\title{
Alterações em características químicas de um Neossolo Litólico húmico cultivado com Pinus taeda, promovidas pela aplicação de lodo celulósico
}

\author{
Shizuo Maeda ${ }^{1}$, Helton Damin da Silva ${ }^{1}$, Antonio Francisco Jurado Bellote ${ }^{1}$
}

Embrapa Florestas, Km 111, CP 319, CEP 83411-000, Colombo, PR, Brasil, maeda@cnpf.embrapa.br; helton@cnpf.embrapa.br; bellote@cnpf.embrapa.br

\begin{abstract}
Resumo - Avaliou-se, em condições de vaso, o efeito da aplicação de lodo celulósico em características químicas do solo e de efluentes resultantes dessa aplicação, em amostras de um Neossolo Litólico húmico coletadas nas camadas 0 a $10 \mathrm{~cm}$ e $10 \mathrm{~cm}$ a $30 \mathrm{~cm}$. Os tratamentos constituídos de doses do lodo, equivalentes a $0 ; 10 ; 20 ; 40$ e $80 \mathrm{Mg} \mathrm{ha}^{-1}$ foram implantados em delineamento inteiramente casualizado. Alíquotas correspondentes às doses do lodo, coletadas na estação de tratamento, foram misturadas ao solo da camada 0 a $10 \mathrm{~cm}$ e acondicionados nos vasos após o preenchimento com o solo da camada $10 \mathrm{~cm}$ a $30 \mathrm{~cm}$. Aos 117 dias após a implantação do ensaio, foram coletadas amostras de solo da camada 0 a $20 \mathrm{~cm}$ e do efluente resultante das aplicações de água para irrigação. Os tratamentos aplicados alteraram as características avaliadas, com exceção dos teores de carbono orgânico e de $\mathrm{Mg}$. Houve aumento do $\mathrm{pH} \mathrm{CaCl}_{2}$, dos teores de $\mathrm{P}, \mathrm{Ca}$ e $\mathrm{K}$ e da saturação por bases, com maior impacto no teor de $\mathrm{P}$. Os teores de $\mathrm{Al}$ trocável, da acidez potencial e da saturação por $\mathrm{Al}$ trocável diminuíram com o aumento das doses do resíduo. Não há evidências de contaminação do solo e da água pela aplicação do resíduo.
\end{abstract}

Termos para indexação: Solos, atributos químicos, resíduo celulósico.

\section{Changes in chemical characteristics of a Litholic Humic Neosol grown with Pinus taeda, promoted by the application of cellulosic residue}

\begin{abstract}
The aim of this work was to evaluate, in vase, the effect of cellulosic residue in soil and chemical characteristics of effluents resulting from that application in Litholic Humic Neosol layers collected in the 0 to 10 and $10 \mathrm{~cm}$ to $30 \mathrm{~cm}$. Doses of sludge, equivalent to $0,10,20,40$ and $80 \mathrm{Mg} \mathrm{ha}^{-1}$ were implanted in a randomized design. Aliquots corresponding to doses of sludge, collected on the treatment were mixed to the soil layer of 0 to $10 \mathrm{~cm}$ and placed in vessels after the completion of the soil layer from $10 \mathrm{~cm}$ to $30 \mathrm{~cm}$. At 117 days after implantation of the test, samples were collected from the soil layer from 0 to $20 \mathrm{~cm}$ and from the effluent resulting from the application of water for irrigation. The treatments changed the characteristics evaluated, except the levels of organic carbon and $\mathrm{Mg}$. There was an increase in $\mathrm{pH}^{-\mathrm{CaCl}_{2}}$, in the levels of $\mathrm{Ca}$, $\mathrm{P}$ and $\mathrm{K}$ and in the base saturation, with greater impact on the content of $\mathrm{P}$. The concentration of exchangeable $\mathrm{Al}$, the potential acidity and exchangeable Al saturation were reduced with increasing doses of the residue. There is no evidence of contamination of soil and water by the application of the residue.
\end{abstract}

Index terms: Soil, attributes, cellulosic residue.

\section{Introdução}

A geração de resíduos é uma das consequências do processamento industrial de matéria-prima. Nas indústrias de celulose e papel, a destinação final de resíduos resultantes do tratamento de efluentes tem sido um dos grandes desafios desse setor. A alternativa de disposição em aterros industriais é onerosa e gera uma responsabilidade com prazo e custo indefinidos (Costa, 2008).
A aplicação de resíduos em áreas de plantios florestais é uma alternativa para descarte desses materiais, solucionando um problema ambiental de disposição, ao mesmo tempo em que contribui para a reposição de nutrientes exportados pela a retirada da biomassa florestal (Guerrini \& Moro, 1994; Bellote et al., 1995; Barreto, 2008). Além de partes de compostos utilizados na digestão da celulose e no tratamento dos efluentes, parte dos nutrientes remanescentes da biomassa vegetal 
processada para a obtenção da celulose permanece no lodo celulósico gerado. Isso os torna excelentes fontes para o acréscimo de matéria orgânica e de nutrientes para a recuperação e manutenção da fertilidade dos solos utilizados para plantios florestais, para os quais normalmente são destinados os solos de baixa fertilidade natural (Bellote et al., 1995).

Embora os lodos entre os quais o celulósico apresentem potencial para utilização como condicionador do solo e fonte de nutrientes, a utilização indiscriminada desses resíduos pode ocasionar prejuízos ambientais, sendo necessário o pleno conhecimento de suas características, principalmente de seus efeitos no ambiente (Bellote et al., 1995; Pires et al., 2005; Balbinot et al., 2006).

O objetivo desse trabalho foi avaliar o efeito de um resíduo celulósico em algumas características químicas do solo e nos efluentes resultantes de sua aplicação em vaso com solo sob cultivo com Pinus taeda L.

\section{Material e métodos}

O estudo foi conduzido em casa de vegetação da Embrapa Florestas, em Colombo, PR. A implantação foi feita em agosto de 2008, utilizando mudas de $P$. taeda com 5,5 meses de idade, originada de sementes coletadas em árvores clonais de primeira geração. Foram utilizados vasos com $15 \mathrm{~cm}$ de diâmetro e $35 \mathrm{~cm}$ de altura, confeccionados com acetato transparente fixado em uma base de concreto, sendo plantada uma muda por vaso. $\mathrm{Na}$ base de concreto foi afixado um equipamento (equipo) para coleta do efluente. Os vasos foram preenchidos com amostras de um Neossolo Litólico húmico (Sistema..,1999), coletado na camada de 0 a $10 \mathrm{~cm}$ e $10 \mathrm{~cm}$ a $30 \mathrm{~cm}$, no Município de Piraí do Sul, PR, sendo obedecida a ordem das camadas no perfil, para o preenchimento dos vasos. As características do solo utilizado encontram-se na Tabela 1, determinadas conforme Silva (1999). Após secagem, peneiramento e homogeneização, porções da amostra do solo foram colocadas nos recipientes.

Os tratamentos constituídos de doses do lodo foram equivalentes, em base seca, a $0 ; 10 ; 20 ; 40$ e $80 \mathrm{Mg}$ $\mathrm{ha}^{-1}$, foram aplicados sob o delineamento estatístico inteiramente ao acaso com quatro repetições. O lodo celulósico utilizado foi coletado na estação de tratamento de efluentes ao final do processo de tratamento. As alíquotas do lodo, secas e moídas, equivalentes às doses aplicadas, foram incorporadas à camada de 0 a $10 \mathrm{~cm}$, sendo o conteúdo de água mantido nesse nível com a aplicação de água destilada na quantidade equivalente ao volume médio de chuvas da região de Piraí do Sul, PR, durante o período de condução do ensaio.

Tabela 1. Características físicas e químicas* do Neossolo Litólico húmico.

\begin{tabular}{|c|c|c|}
\hline \multirow{2}{*}{ Variáveis } & \multicolumn{2}{|c|}{ Camadas } \\
\hline & 0 a $10 \mathrm{~cm}$ & $10 \mathrm{~cm}$ a $30 \mathrm{~cm}$ \\
\hline \multicolumn{3}{|c|}{ Características físicas } \\
\hline Areia $-\mathrm{g} \mathrm{kg}^{-1}$ & 774,00 & 759,00 \\
\hline Silte $-\mathrm{g} \mathrm{kg}^{-1}$ & 49,00 & 55,00 \\
\hline Argila $-\mathrm{g} \mathrm{kg}^{-1}$ & 177,00 & 186,00 \\
\hline \multicolumn{3}{|c|}{ Características químicas } \\
\hline $\mathrm{pH} \mathrm{CaCl}{ }_{2}$ & 3,83 & 3,88 \\
\hline $\mathrm{C}-\mathrm{g} \mathrm{dm}^{-3}$ & 27,18 & 15,94 \\
\hline $\mathrm{P}-\mathrm{mg} \mathrm{dm^{-3 }}$ & 2,41 & 1,65 \\
\hline $\mathrm{K}-\mathrm{cmol}_{\mathrm{c}} \mathrm{dm}^{-3}$ & 0,06 & 0,04 \\
\hline $\mathrm{Ca}-\mathrm{cmol}_{\mathrm{c}} \mathrm{dm}^{-3}$ & 0,11 & 0,10 \\
\hline $\mathrm{Mg}-\mathrm{cmol}_{\mathrm{c}} \mathrm{dm}^{-3}$ & 0,25 & 0,20 \\
\hline $\mathrm{Al}-\mathrm{cmol}_{\mathrm{c}} \mathrm{dm}^{-3}$ & 2,63 & 2,63 \\
\hline$(\mathrm{H}+\mathrm{Al})-\mathrm{cmol}_{\mathrm{c}} \mathrm{dm}^{-3}$ & 9,70 & 8,36 \\
\hline $\mathrm{SB}-\mathrm{cmol}_{\mathrm{c}} \mathrm{dm}^{-3}$ & 0,42 & 0,34 \\
\hline $\mathrm{T}-\mathrm{cmol}_{\mathrm{c}} \mathrm{dm}^{-3}$ & 10,12 & 8,70 \\
\hline$V-\%$ & 4,10 & 3,90 \\
\hline$m-\%$ & 86,4 & 88,8 \\
\hline
\end{tabular}

Aos 117 dias após a implantação, foram coletadas amostras de efluente líquido percolado. Para isso, foram aplicados 2 L de água destilada e deionizada em cada vaso, sendo a água coletada por meio do equipamento adaptado na base de concreto. Após a coleta do efluente, amostras de solo da camada 0 a $20 \mathrm{~cm}$ foram coletadas para análises de fertilidade (Silva, 1999). Nessas amostras, além de determinações de rotina, foram determinados os teores totais de $\mathrm{Ba}, \mathrm{Cd}, \mathrm{Cr}, \mathrm{Pb}, \mathrm{Mo}, \mathrm{Cu}$ e $\mathrm{Zn}$ por meio da digestão das amostras com água régia $\left(\mathrm{HNO}_{3}+\mathrm{HCl}\right.$ - relação 3:1). No efluente coletado ao final do período de condução do ensaio, foram determinados os teores de $\mathrm{Ba}, \mathrm{Cd}, \mathrm{Cr}, \mathrm{Pb}, \mathrm{Cu}, \mathrm{Zn}$, nitrato e nitrito conforme American Public Health Association (1998). Adicionalmente, no efluente líquido, foi determinada a condutividade elétrica, utilizando equipamento portátil. As determinações de rotina para fins de avaliação da fertilidade foram feitas em todas as repetições de todos 
os tratamentos, enquanto as demais foram realizadas em uma amostra composta por subamostras de solo e do efluente dos tratamentos 0 e $80 \mathrm{Mg} \mathrm{ha}^{-1}$.

Os resultados analíticos referentes à caracterização do lodo celulósico encontram-se na Tabela 2.

Os dados obtidos foram submetidos à análise de variância e, quando significativos, as médias de cada variável foram submetidas ao teste de Tukey a $5 \%$ e à análise de regressão.

Tabela 2. Resultados de análise química realizada para fins de caracterização do lodo celulósico. Valores obtidos na massa seca.

\begin{tabular}{|c|c|c|}
\hline Parâmetro & Unidade & Valor \\
\hline pH água & - & 7,7 \\
\hline Teor de umidade & $\%$ & 89,63 \\
\hline Cinzas & $\%$ & 3,22 \\
\hline Matéria Orgânica & $\%$ & 7,15 \\
\hline C total & $\%$ & 3,97 \\
\hline $\mathrm{N}$ total & $\%$ & $<0,01$ \\
\hline S total & $\%$ & 1,16 \\
\hline $\mathrm{P}_{2} \mathrm{O}_{5}$ total & $\%$ & 0,50 \\
\hline Fenóis total & $\mathrm{mg} \mathrm{kg}^{-1}$ & 5,35 \\
\hline $\mathrm{Al}$ & $\mathrm{mg} \mathrm{kg}^{-1}$ & $76.160,9$ \\
\hline $\mathrm{Ba}$ & $\mathrm{mg} \mathrm{kg}^{-1}$ & $<50$ \\
\hline $\mathrm{Cd}$ & $\mathrm{mg} \mathrm{kg}^{-1}$ & $<10$ \\
\hline $\mathrm{Ca}$ & $\mathrm{mg} \mathrm{kg}^{-1}$ & $2.169,81$ \\
\hline $\mathrm{Pb}$ & $\mathrm{mg} \mathrm{kg}^{-1}$ & $<50$ \\
\hline $\mathrm{Cu}$ & $\mathrm{mg} \mathrm{kg}^{-1}$ & 11,42 \\
\hline Cr total & $\mathrm{mg} \mathrm{kg}^{-1}$ & 6,26 \\
\hline $\mathrm{Fe}$ & $\mathrm{mg} \mathrm{kg}^{-1}$ & $4.374,28$ \\
\hline $\mathrm{Mg}$ & $\mathrm{mg} \mathrm{kg}^{-1}$ & 768,49 \\
\hline $\mathrm{Mn}$ & $\mathrm{mg} \mathrm{kg}^{-1}$ & 167 \\
\hline Mo & $\mathrm{mg} \mathrm{kg}^{-1}$ & $<10$ \\
\hline $\mathrm{K}$ & $\mathrm{mg} \mathrm{kg}^{-1}$ & 208,71 \\
\hline $\mathrm{Na}$ & $\mathrm{mg} \mathrm{kg}^{-1}$ & $2.065,44$ \\
\hline $\mathrm{Zn}$ & $\mathrm{mg} \mathrm{kg}^{-1}$ & 31,58 \\
\hline $\mathrm{PN}$ & $\%$ & 2,56 \\
\hline
\end{tabular}

\section{Resultados e discussão}

A aplicação de doses do lodo celulósico promoveu alterações em todas as características avaliadas no solo, com exceção dos teores de carbono orgânico (CO) e de Mg (Tabela 3 e Figuras 1, 2, 3).
Dentre as alterações observadas, pode-se destacar o aumento no teor de P com teor inicial de 2,12, elevandose para $6,71 \mathrm{mg} \mathrm{dm}^{-3}$ na maior dose do lodo celulósico (Figura 1). O aumento observado no teor de P pode ser atribuído ao conteúdo deste elemento no lodo aplicado $\left(0,5 \%\right.$ de $\left.\mathrm{P}_{2} \mathrm{O}_{5}\right)$, o que corresponde à aplicação de 0 , $50,100,200$ e $400 \mathrm{~kg} \mathrm{ha}^{-1}$ de $\mathrm{P}_{2} \mathrm{O}_{5}$, respectivamente, conforme os tratamentos $0,10,20,40$, e $80 \mathrm{Mg} \mathrm{ha}^{-1}$. Além disso, os ácidos orgânicos que podem ter sido liberados pelos processos de decomposição do lodo celulósico podem alterar a dinâmica do $\mathrm{P}$, diminuindo a sua adsorção pela competição dos sítios de adsorção, diminuindo a fixação do P (Haynes, 1984). Por ser um dos nutrientes mais deficientes na maioria dos solos do Brasil, a capacidade do resíduo celulósico em aumentar o teor de $\mathrm{P}$ o potencializa como uma alternativa aos produtos utilizados para o fornecimento de P às plantas. Guerrini \& Moro (1994), em estudo conduzido para avaliar o efeito de lodo celulósico resultante do tratamento de efluentes da fabricação de celulose em Latossolo Vermelho-Amarelo Distrófico também observaram aumentos no teor de $\mathrm{P}$ como efeito da aplicação de doses do resíduo.

$\mathrm{O}$ aumento das doses de lodo aplicadas promoveu a redução da acidez do solo, mostrada pelo aumento no valor do $\mathrm{pH} \mathrm{em} \mathrm{CaCl}_{2}$, com o maior valor sendo observado para a maior dose estudada. Houve, ainda, a redução no teor de Al trocável e na saturação por $\mathrm{Al}(\mathrm{m})$, com os menores valores observados na maior dose estudada (Figura 3). Apesar do baixo poder de neutralização $(\mathrm{PN})$ da acidez apresentado pelo resíduo (Tabela 2), em função das doses estudadas, foram verificados aumentos no $\mathrm{pH}$ até a maior dose, embora os incrementos tenham sido reduzidos, sendo esses resultados semelhantes aos observados por Guerrini \& Moro (1994), em estudo realizado para avaliar o efeito de resíduo celulósico em plantio de Eucalyptus grandis.

Para espécies tolerantes à acidez e à presença de $\mathrm{Al}$, como é o caso do $P$. taeda, a redução da acidez e da saturação por Al não é fundamental para a sua exploração econômica. A redução observada no teor de $\mathrm{Al}$ trocável pode indicar que a forma química do Al presente no lodo celulósico apresenta baixa solubilidade ou é insolúvel em água, uma vez que o seu teor no resíduo estudado é elevado (Tabela 2).

Os aumentos observados nos teores de $\mathrm{K}$ e de $\mathrm{Ca}$ resultaram na elevação da saturação por bases (V\%) (Tabela 3 e Figura 2). Embora apresentando baixos teores 
de $\mathrm{K}$ e de $\mathrm{Ca}$ (Tabela 2), em função das doses estudadas, as quantidades dos nutrientes aplicadas foram suficientes para promover a elevação dos teores dos mesmos no solo, principalmente nas maiores doses. No caso do K, os aumentos observados foram suficientes para promover mudança na classe de interpretação do teor encontrado na maior dose que passou da faixa de teor baixo para médio (Bellote \& Silva, 2005). A aplicação de doses de resíduo celulósico com alto teor de Ca no estudo realizado por Gerrini \& Moro (1994) resultaram em aumentos nos teores do elemento no solo, enquanto os teores de K no solo não foram alterados, em função do baixo teor do elemento no lodo.

A presença de metais pesados e o seu acúmulo no solo são aspectos ambientais que devem ser avaliados para a viabilização do uso de resíduos em silvicultura, e a obtenção de dados sobre o acúmulo desses elementos químicos no solo é feita pela análise dos teores totais dos mesmos. Os teores de $\mathrm{Ba}, \mathrm{Cu}, \mathrm{Cr}$ e $\mathrm{Zn}$ detectados na maior dose estudada ficaram abaixo dos teores limites de qualidade apresentados por Companhia de Tecnologia de Saneamento Ambiental (2005), para o solo. Com relação aos teores de $\mathrm{Cd}$, $\mathrm{Pb}$ e Mo no solo, os limites de detecção dos métodos analíticos utilizados foram maiores que os teores limites de qualidade do solo apresentado por Companhia de Tecnologia de Saneamento Ambiental (2005), não permitindo qualquer tipo de comparação entre os tratamentos com esses valores. Por serem nutrientes para as plantas, a presença de $\mathrm{Cu}$ e $\mathrm{Zn}$ pode ser fator favorável à aplicação do lodo celulósico em condições de solos deficientes e de culturas exigentes nos mesmos. O Mo é importante para espécies de plantas dependentes da fixação simbiótica de $\mathrm{N}$ atmosférico, uma vez que o elemento é componente de enzimas localizadas em nódulos nas raízes de plantas fixadoras de N (Dechen \& Nachtigall, 2006).

Tabela 3. Valores das características químicas do solo com diferentes doses de lodo cultivado com Pinus taeda.

\begin{tabular}{|c|c|c|c|c|c|c|c|c|c|c|}
\hline \multirow{2}{*}{$\begin{array}{c}\text { Dose } \\
\left(\mathrm{Mg} \mathrm{ha}^{-1}\right)\end{array}$} & \multirow{2}{*}{$\begin{array}{c}\mathrm{pH} \\
\mathrm{CaCl}_{2}\end{array}$} & \multirow{2}{*}{$\begin{array}{c}\mathrm{CO} \\
\left(\mathrm{g} \mathrm{dm}^{-3}\right) \\
\end{array}$} & \multirow{2}{*}{$\begin{array}{c}P \\
\left(\mathrm{mg} \mathrm{dm}^{-3}\right)\end{array}$} & $\mathbf{K}$ & $\mathrm{Ca}$ & Mg & Al & $\mathbf{H}+\mathbf{A l}$ & $\mathbf{V}$ & $\mathbf{m}$ \\
\hline & & & & \multicolumn{5}{|c|}{$\left(\mathrm{cmol}_{\mathrm{c}} \mathrm{dm}^{-3}\right)$} & \multicolumn{2}{|c|}{$(\%)$} \\
\hline 0 & $3,97 \mathrm{e}$ & 17,89 a & $2,12 \quad \mathrm{c}$ & $0,050 \mathrm{~d}$ & $0,21 \mathrm{c}$ & $0,32 \mathrm{a}$ & $3,04 \mathrm{a}$ & $10,65 \mathrm{a}$ & $5,16 \mathrm{~d}$ & $83,98 \mathrm{a}$ \\
\hline 10 & $4,05 \mathrm{~d}$ & $16,16 \mathrm{a}$ & $3,77 \mathrm{bc}$ & $0,052 \mathrm{~d}$ & $0,25 \mathrm{c}$ & $0,37 \mathrm{a}$ & $2,30 \mathrm{~b}$ & $9,35 \mathrm{~b}$ & $6,63 \mathrm{~cd}$ & $77,47 \mathrm{~b}$ \\
\hline 20 & $4,12 \mathrm{c}$ & $16,61 \mathrm{a}$ & $5,11 \mathrm{ab}$ & $0,062 \mathrm{c}$ & $0,31 \mathrm{c}$ & $0,40 \mathrm{a}$ & $2,18 \mathrm{~b}$ & $9,53 \mathrm{~b}$ & $7,49 \mathrm{c}$ & $73,74 \mathrm{~b}$ \\
\hline 40 & $4,23 \mathrm{~b}$ & $20,50 \mathrm{a}$ & $5,85 \mathrm{ab}$ & $0,066 \mathrm{~b}$ & $0,48 \mathrm{~b}$ & $0,41 \mathrm{a}$ & $1,87 \mathrm{bc}$ & $8,08 \mathrm{c}$ & $10,72 \mathrm{~b}$ & $65,73 \mathrm{c}$ \\
\hline 80 & $4,41 \mathrm{a}$ & $18,03 \mathrm{a}$ & $6,71 \mathrm{a}$ & $0,070 \mathrm{a}$ & $0,71 \mathrm{a}$ & $0,39 \mathrm{a}$ & $1,34 \mathrm{c}$ & $6,95 \mathrm{~d}$ & $14,48 \mathrm{a}$ & $53,16 \mathrm{~d}$ \\
\hline CV - \% & 0,67 & 14,12 & 19,88 & 8,40 & 14,94 & 15,55 & 11,93 & 5,35 & 7,79 & 3,72 \\
\hline
\end{tabular}

$\mathrm{CV}=$ Coeficiente de variação; * valores seguidos por letras iguais nas colunas não diferem significativamente entre si (Tukey $5 \%$ ).

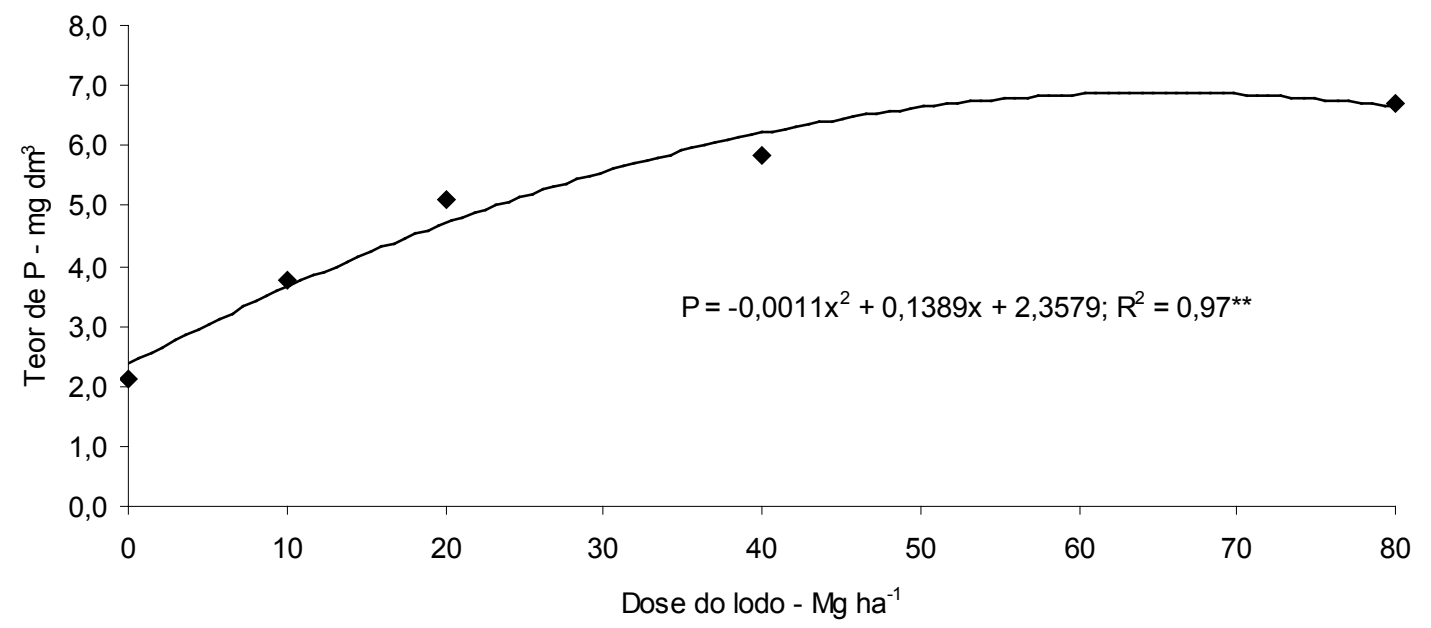

Figura 1. Teores de P no solo como resultado da aplicação de doses de lodo de estação de tratamento de efluentes de indústria de celulose. $* *$ significativo a $1 \%$. 

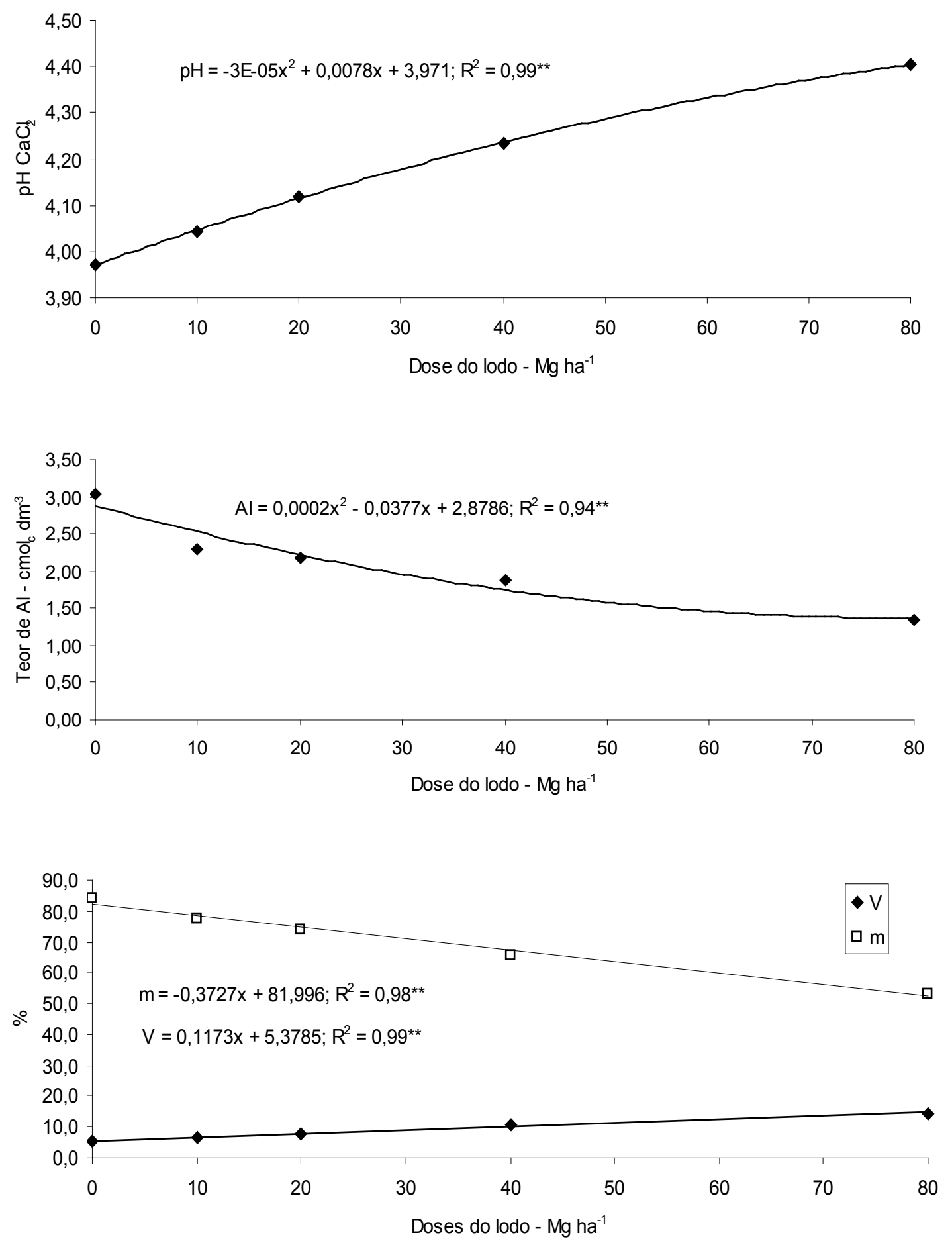

Figura 2. Características químicas do solo como resultado da aplicação de doses de lodo de estação de tratamento de efluentes de indústria de celulose. ${ }^{* *}$ significativo a $1 \%$. 

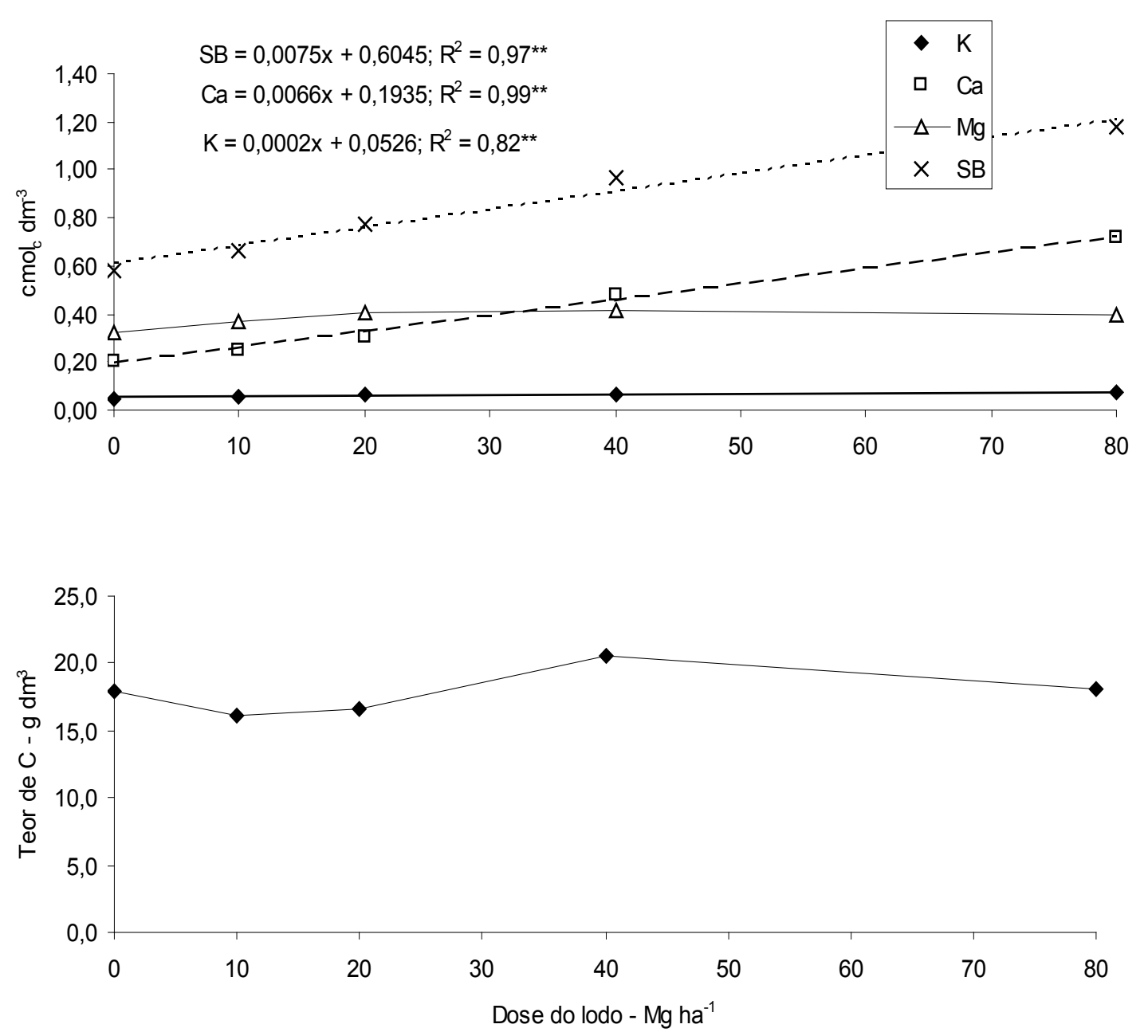

Figura 3. Efeito da aplicação de doses de lodo de estação de tratamento de efluentes de indústria de celulose nos teores de K, $\mathrm{Ca}, \mathrm{Mg}$ e soma de bases (SB), figura superior, e no teor de carbono orgânico (C), figura inferior. ** significativo a $1 \%$.

Além da contaminação do solo, a água do lençol freático pode ser contaminada por metais pesados contidos nos resíduos aplicados. No efluente coletado (água percolada), todas as variáveis analisadas apresentaram teores abaixo do valor máximo permitido (VMP) na ausência e na maior dose do lodo, conforme valores padrões apresentados por Brasil (2005), não havendo indícios aparentes de contaminação provocada pela aplicação do lodo (Tabela 4).

Os teores de $\mathrm{Ba}, \mathrm{Cd}, \mathrm{Pb}, \mathrm{Cu}, \mathrm{Cr}$ total, $\mathrm{Mo}$ e $\mathrm{Zn}$, contidos no lodo celulósico estudado, encontram-se abaixo dos valores máximos permitidos pela Resolução 375/2006 (Brasil, 2006), embora esta resolução seja específica para lodo de esgoto urbano. $\mathrm{Na}$ ausência de legislação específica, a Resolução 375/2006 tem sido utilizada como referência (Costa, 2008). Em função dos baixos teores desses elementos presentes no lodo celulósico estudado, "a carga acumulada teórica permitida de substâncias inorgânicas pela aplicação de lodo de esgoto ou produto derivado em solos agrícolas" estabelecida pela mencionada resolução não foi atingida mesmo na maior dose estudada (Tabela 5), o que pode explicar os efeitos observados entre os tratamentos estudados.

A condutividade elétrica medida no efluente coletado foi significativamente elevada pela aplicação de doses do lodo (Figura 4), indicando a lixiviação de íons presentes no resíduo estudado (Tabela 2). 
Tabela 4. Resultados de análise química de amostras de solo e efluente, formuladas por amostras coletadas nos tratamentos 0 e $80 \mathrm{Mg} \mathrm{ha}^{-1}$ e teores de qualidade do solo (Companhia de Tecnologia de Saneamento Ambiental, 2005) (CETESB) e valor máximo permitido (VMP) na água (Brasil, 2005).

\begin{tabular}{|c|c|c|c|c|c|c|}
\hline \multirow{4}{*}{ Variáveis } & \multicolumn{3}{|c|}{ Solo } & \multicolumn{3}{|c|}{ Efluente } \\
\hline & \multicolumn{2}{|c|}{ Tratamento } & \multirow{2}{*}{$\begin{array}{c}\text { (CETESB) } \\
\text { Nível de qualidade }\end{array}$} & \multicolumn{2}{|c|}{ Tratamento } & \multirow{2}{*}{$\begin{array}{c}\text { (Brasil, 2005) } \\
\text { VMP }\end{array}$} \\
\hline & 0 & 80 & & $\mathbf{0}$ & 80 & \\
\hline & \multicolumn{3}{|c|}{$\left(\mathrm{mg} \mathrm{kg}^{-1}\right)$} & \multicolumn{3}{|c|}{$\left(\mathrm{mg} \mathrm{L}^{-1}\right)$} \\
\hline $\mathrm{Ba}$ & $<40,81$ & $<40,83$ & 75 & $<0,50$ & $<0,50$ & 0,7 \\
\hline $\mathrm{Cd}$ & $<8,16$ & $<8,17$ & $<0,5$ & $<0,0005$ & $<0,0005$ & 0,005 \\
\hline $\mathrm{Pb}$ & $<40,81$ & $<40,83$ & 17 & $<0,005$ & $<0,005$ & 0,01 \\
\hline $\mathrm{Cu}$ & $<8,16$ & 9,96 & 35 & $<0,005$ & $<0,005$ & 2 \\
\hline Cr total & 10,28 & 11,11 & 40 & $<0,005$ & $<0,005$ & 0,05 \\
\hline Mo & $<8,16$ & $<8,17$ & $<4$ & - & - & - \\
\hline $\mathrm{Zn}$ & 35,5 & 32,28 & 60 & - & - & - \\
\hline $\mathrm{NO}_{3}$ & - & - & - & $<0,10$ & $<0,10$ & 10 \\
\hline $\mathrm{NO}_{2}$ & - & - & - & 0,02 & 0,04 & 1 \\
\hline
\end{tabular}

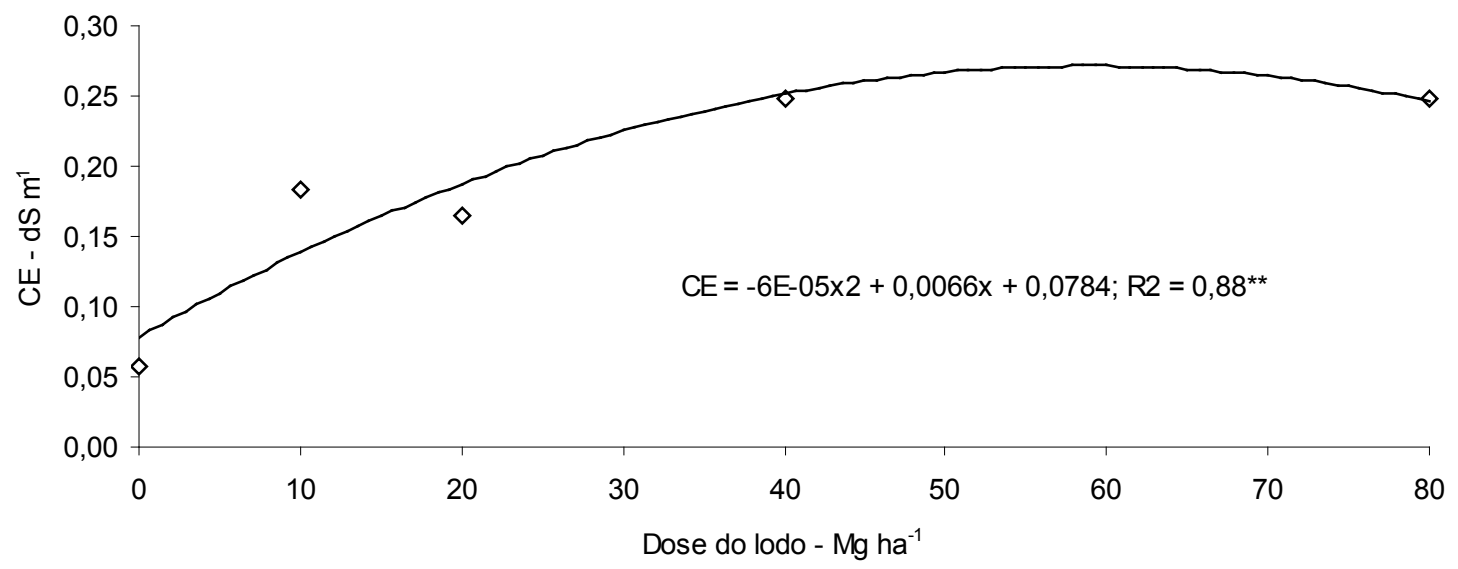

Figura 4. Condutividade elétrica (CE) do efluente, como resultado da aplicação de doses de lodo celulósico. ** significativo a 1\%. 
Tabela 5. Estimativas das quantidades de elementos químicos aplicadas conforme as doses estudadas.

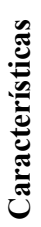

Doses do lodo celulósico

$\left(\mathrm{Mg} \mathrm{ha}^{-1}\right)$

\begin{tabular}{llll}
\hline 10 & 20 & 40 & 80 \\
\hline
\end{tabular}

$\left(\mathrm{kg} \mathrm{ha}^{-1}\right)$

\begin{tabular}{lrrrr}
\hline $\mathrm{C}$ total & 397,00 & 794,00 & $1.588,00$ & $3.176,00$ \\
$\mathrm{~N}$ total & 1,00 & 2,00 & 4,00 & 8,00 \\
$\mathrm{~S}$ total & 116,00 & 232,00 & 464,00 & 928,00 \\
$\mathrm{P}_{2} \mathrm{O}_{5}$ total & 50,00 & 100,00 & 200,00 & 400,00 \\
$\mathrm{Al}$ & 761,61 & $1.523,22$ & $3.046,44$ & $6.092,87$ \\
$\mathrm{Ba}$ & 0,50 & 1,00 & 2,00 & 4,00 \\
$\mathrm{Cd}$ & 0,10 & 0,20 & 0,40 & 0,80 \\
$\mathrm{Ca}$ & 21,70 & 43,40 & 86,79 & 173,58 \\
$\mathrm{Cu}$ & 0,11 & 0,23 & 0,46 & 0,91 \\
$\mathrm{Cr}$ total & 0,06 & 0,13 & 0,25 & 0,50 \\
$\mathrm{Fe}$ & 43,74 & 87,49 & 174,97 & 349,94 \\
$\mathrm{Mg}$ & 7,68 & 15,37 & 30,74 & 61,48 \\
$\mathrm{Mn}$ & 1,67 & 3,34 & 6,68 & 13,36 \\
$\mathrm{Mo}$ & 0,10 & 0,20 & 0,40 & 0,80 \\
$\mathrm{~K}$ & 2,09 & 4,17 & 8,35 & 16,70 \\
$\mathrm{Na}$ & 20,65 & 41,31 & 82,62 & 165,24 \\
$\mathrm{Zn}$ & 0,32 & 0,63 & 1,26 & 2,53 \\
\hline
\end{tabular}

\section{Conclusões}

A aplicação de lodo de estação de tratamento de efluente de fábrica de celulose promove alterações em propriedades químicas do solo estudado: aumenta os teores de $\mathrm{Ca}, \mathrm{K}$ e $\mathrm{P}$ e o nível de saturação por bases, com destaque para o teor de $\mathrm{P}$; reduz a acidez e o teor de $\mathrm{Al}$ trocável, bem como sua saturação e a acidez potencial; não altera os teores de $\mathrm{Mg}$ e da matéria orgânica, e não contamina o solo e a água com $\mathrm{Ba}, \mathrm{Cu}, \mathrm{Cd}, \mathrm{Cr}, \mathrm{Pb}, \mathrm{Mo}$ e $\mathrm{Zn}$.

\section{Referências}

\section{AMERICAN PUBLIC HEALTH ASSOCIATION. Standard} methods for the examination of water and wastewater. 20 . Ed. Washington, DC, 1998. Paginação irregular.

BALBINOT JUNIOR, A.A.; TÔRRES, A.N.L.; FONSECA, J. A. da; TEIXEIRA, J.R.; NESI, C.N. Alteração em características químicas de um solo ácido pela aplicação de calcário e resíduos de reciclagem de papel. Revista de ciências Agroveterinárias, Lages, v.5, n. 1, p. 16-25, 2006.
BARRETO, V. C. de M. Resíduos de indústria de celulose e papel na fertilidade do solo e no desenvolvimento de eucalipto. 2008. 67f. Tese (Doutorado em Agronomia) - Faculdade de Ciências Agrárias e Veterinária - UNESP, Campus de Jaboticabal.

BELLOTE, A. F. J.; FERREIRA, C. A.; SILVA, H. D. da; ANDRADE, G. de C. Efecto de la aplicación de ceniza de caldera y residuo de celulosa en el suelo y en el crecimiento de Eucalyptus grandis. In.: SIMPOSIO IUFRO PARA CONO SUR SUDAMERICANO; Manejo Nutritivo de Plantaciones Forestales, 1995, Valdivia. Actas. Valdivia: Universidad Austral de Chile, Faculdad de Ciencias Forestales, 1995. p.317-323.

BELlote, A. F. J.; SILVA, H. da S. Cultivo do Pinus: adubação. In: SHIMIZU, J. Y.; MEDRADO, M. J. S. Cultivo do pinus. Colombo: Embrapa Florestas, 2005. (Embrapa Florestas. Sistemas de Produção, 5). Diponível em: $<$ http:// sistemasdeproducao.cnptia.embrapa.br/FontesHTML/Pinus/ CultivodoPinus/09_adubacao.htm>. Acesso em: 17 ago. 2009

BRASIL. Conselho Nacional do Meio Ambiente. Resolução n. 375, de 30 de agosto de 2006. Diário Oficial Republica Federativa do Brasil. Brasília, DF, 30 de agosto de 2006. Seção 1, p. 141-146.

BRASIL. Ministério da Saúde. Secretaria de Vigilânica em Saúde. Coordenação-Geral de Vigilância em Saúde Ambiental. Portaria MS n. ${ }^{\circ}$ 518/2004 / Ministério da Saúde, Secretaria de Vigilância em Saúde, Coordenação- Geral de Vigilância em Saúde Ambiental - Brasília: Editora do Ministério da Saúde, 2005. 28 p. - (Série E. Legislação em Saúde). Disponível em: <http://portal.saude.gov.br/ portal/arquivos/pdf/portaria_518_2004.pdf $>$. Acesso em 18 ago. 2008.

\section{COMPANHIA DE TECNOLOGIA DE SANEAMENTO}

AMBIENTAL (CETESB). Decisão de diretoria n. 195-2005 - E, de 23 de novembro de 2005. Disponível em : <http://www.cetesb. sp.gov.br/Solo/relatorios/tabela_valores_2005.pdf $>$. Acesso em: 18 ago. 2009.

COSTA, E. R. O. Alterações químicas no solo e na água de percolação após aplicação de resíduos de fabrica de papel reciclado em Pinus taeda L. 2008. 138. F. Dissertação (Mestrado em Engenharia Florestal) - Setor de Ciências Agrárias, Universidade Federal do Paraná, Curitiba.

DECHEN, A. R.; NASHTIGALL, G. R. Micronutrientes. In. FERNANDES, M. S. (Ed.). Nutrição Mineral de plantas. Viçosa: Sociedade Brasileira de Ciência do Solo, 2006. p. 327-354.

GUERRINI, 1. A.; MORO, L. Influência da aplicação de resíduos industriais de fabrica de celulose e papel em plantios de eucalipto: efeitos no solo e na planta. In: SEMINÁRIO SOBRE USO DE RESÍDUOS INDUSTRIAIS E URBANOS EM FLORESTAS, 1994, Botucatu. [Anais]. Botucatu: UNESP. Faculdade de Ciências Econômicas, 1994. p.188-215.

HAYNES, R. J. Lime and phosphate in soil plant sistem. Advances in Agronomy, v. 37, p. 249-315, 1967.

PIRES, A.M.M., MATTIAZZO, M.E. BERTO, R.S.; GUILHERME, L.R.G.; MARCHI, G. Extração de metais pesados fitodisponíveis em solos tratados com lodo de esgoto: uso de ácidos orgânicos. Comunicado Técnico, Jaguaraiúna. n. 28, Jul. 2005. 
Alterações em características químicas de um Neossolo Litólico húmico cultivado com Pinus taeda, promovidas pela aplicação de 35 lodo celulósico

SILVA, F. C. da (Org.). Manual de análises químicas de solos, plantas e fertilizantes. Brasília, DF: Embrapa Comunicação para Transferência de Tecnologia; Rio de Janeiro: Embrapa Solos; Campinas: Embrapa Informática Agropecuária, 1999. 370 p.
SISTEMA Brasileiro de Classificação de Solos. Brasília, DF: Embrapa Produção de Informação; [Rio de Janeiro]: Embrapa Solos, 1999. Brasília, DF: Embrapa Produção de Informação; [Rio de Janeiro]: Embrapa Solos, 1999. 412 p.

Recebido em 02 de setembro de 2009 e aprovado em 09 de fevereiro de 2011 